REFEREN CES

1 Wylie, F. J. (1968). The Use of Radar at Sea, p. 243.

2 Wylie, F. J. (1970). Choosing and Using Ship's Radar, Ch. I.

3 Watt, J. and Piercy, B. C. (1969). A new marine radar display system. This Journal, 22, 205 .

4 Embling, C. A. and Stewart, J. P. (1968). A history recording radar display with prediction. This Journal, 21, 471 .

5 Les moyens automatiques: l'anti-collision ATAW, Navigation (Paris), 17, 311 , July 1969 .

6 Wylie, F. J. (1965). Radar as an anti-collision aid: the ultimate essentials in presentation. This Journal, 18, 232 .

\title{
Spherical Triangles with Integral-degree Parts
}

\author{
D. H. Sadler
}

IN certain esoteric mathematical and computing circles there is, or used to be before the advent of the electronic computer, an interest in near-integral solutions of incommensurable problems. Apart from aesthetic considerations such solutions can have valuable applications in the checking of methods of computation; this is the excuse for the following note.

The investigation from which it arises was itself a by-product. As part of the British contribution to the new Sight Reduction Tables for Marine Navigation (H.O. 229 in U.S.A.; H.D. 605 in the United Kingdom) it was necessary to examine carefully each of the approximately 20 million figures in the six volumes; although the setting was computer-controlled and numerically checked, only visual examination could detect indistinct or broken figures. Such examination is extremely arduous and calls for great powers of concentration if its purpose is not to be wasted. To provide an incentive prizes were offered for finding the combinations of altitude and azimuth that were closest to integral degrees; the examiners could, of course, only pick out the combinations of altitudes ending in 00.0 and azimuths ending in $0 \%$ (about $I$ in 6000), and the closest is then a matter of chance, determined by recomputationproviding incidentally a series of independent checks.

An analysis of the 20-30 closest pairs (with tolerances of about \pm 0.0005 ; many are not independent) immediately reveals what would have been obvious in a direct investigation, namely that they all belong to two special classes; these are described below as $(a)$ and $(b)$.

Class $(a)$ is the more interesting since all six parts of the spherical triangle are near-integral; two angles are equal respectively to their opposite sides, while the sum of the third angle and its opposite side is $180^{\circ}$. The three best examples are tabulated in Table 1 . 
TABLE I. NeAR-INTEgral SOLUTIONS

\begin{tabular}{lllllll} 
No. & $\begin{array}{l}\text { Local } \\
\text { hour } \\
\text { angle }\end{array}$ & $\begin{array}{c}\text { Declin- } \\
\text { ation }\end{array}$ & $\begin{array}{c}\text { Lati- } \\
\text { tude }\end{array}$ & $\begin{array}{c}\text { Altitude } \\
\text { angle }\end{array}$ & $\begin{array}{c}\text { Azimuth } \\
\text { angle } \\
\text { (errors in units of o:0oo or) }\end{array}$ & $\begin{array}{c}\text { Parallactic } \\
\text { angle } \\
\text { o: }\end{array}$ \\
\hline
\end{tabular}

\begin{tabular}{|c|c|c|c|c|c|c|}
\hline & \multicolumn{6}{|c|}{ Class (a) } \\
\hline & 。 & 。 & 。 & 。 & 。 & 。 \\
\hline \multirow{3}{*}{ I } & 22 & $5^{8}$ & 41 & $68(-13)$ & $32(-20)$ & $131(+$ \\
\hline & 32 & 68 & 41 & $5^{8}(-14)$ & $22(-9)$ & $1311+$ \\
\hline & 131 & 68 & 58 & $41(+18)$ & $22(+6)$ & $32(+$ \\
\hline \multirow{3}{*}{2} & 18 & 63 & $4^{8}$ & $72(+24)$ & $27\left(+3^{8}\right)$ & $13^{8}(-$ \\
\hline & 27 & 72 & 48 & $63(+26)$ & $18(+17)$ & $13^{8}(-$ \\
\hline & 138 & 72 & 63 & $4^{8}(-31)$ & $18(-11)$ & $27(-$ \\
\hline \multirow{4}{*}{3} & 37 & 6 & 12 & $53(+11)$ & $96\left(-14^{2}\right)$ & $78(+$ \\
\hline & 78 & 6 & 53 & $12(+43)$ & $96(-87)$ & $37(+$ \\
\hline & 96 & 12 & 53 & $6(-86)$ & $78(-43)$ & $37(-$ \\
\hline & \multicolumn{6}{|c|}{ Class $(b)$} \\
\hline I & 50 & 36 & 7 & $36(-17)$ & $50(-14)$ & 109.98 \\
\hline 2 & 63 & 32 & 18 & $32(-20)$ & $63(-24)$ & $87 \cdot 75$ \\
\hline 3 & 63 & 36 & 26 & $3^{6}(-19)$ & $63(-27)$ & $81 \cdot 84$ \\
\hline
\end{tabular}

Transposition of declination and latitude provides six sets of integral-degree values of L.H.A., Dec. and Lat., leading to near-integral values of the respondents Alt., Az. and P.A.; the errors given in parentheses are in units of $0.000 \mathrm{OI}$, and in the sense that $68^{\circ}(-13)$ represents a true value of $67^{\circ} .99987$.

Class $(b)$ corresponds to an isosceles triangle in which the altitude and azimuth angle are nearly equal (numerically) to the declination and local hour angle; in general the parallactic angle is not integral, and transposition is not possible. Three examples are tabulated in Table $I$.

The number of pairs in both classes is in accord with expectation on the assumption of random distribution of rounding-offs.

If the differences from integral values are minimized, the errors are much reduced from those given and roughly correspond to those arising from the use of six-figure trigonometrical tables; thus the values may be regarded as integral degrees for navigational calculations and may be used for numerical examples in order to avoid interpolation in tables or to check the output of mechanical devices.

In general, azimuth is required to a smaller precision than altitude; much closer approximations to near-integral altitudes alone are possible. The following examples (Table II), which are taken from the examination of a small sample, indicate that seven-figure tables will be inadequate to show the discrepancy; they also indicate that, in order to ensure a high probability of correct roundingoff in the printed tables, the computations must be made with at least eight figures. 
TABLE II. Near-integral altitudes

\begin{tabular}{rrrrcc}
\hline L.H.A. & Lat. & Dec. & Alt. & $\begin{array}{c}\text { Error } \\
0 \% 000001\end{array}$ & $\begin{array}{c}\text { Azimuth } \\
\text { angle }\end{array}$ \\
\hline 0 & 0 & 0 & 0 & 0 & 0 \\
42 & 75 & 78 & 80 & +6 & 53.24 \\
138 & 45 & 56 & 17 & +10 & 23.03 \\
59 & 55 & 14 & 29 & -10 & 108.02 \\
119 & 65 & 72 & 53 & +10 & 26.69 \\
106 & 72 & 24 & 18 & -11 & 67.42 \\
123 & 9 & 72 & 1 & +12 & 15.02 \\
& & & & & \\
\hline
\end{tabular}

If the initial object had been to discover such near-integral solutions, it would have been almost trivial to have programmed the computer to call attention to them when doing the basic calculations.

Acknowledgment is made to Mrs. M. E. Buontempo, Mrs. K. A. Long and Mrs. L. V. Morrison for the care taken in the examination, and to Mr. G. E. Taylor for the recomputations.

\title{
Simplified Tidal Calculations
}

\author{
A. N. Black
}

THE Admiralty Tide Tables give the utmost accuracy in tidal calculations, but at the cost of a number of tedious interpolations. Many seamen, particularly those in small vessels, would be willing to sacrifice some of this accuracy if they could have a simpler form of calculation. In any case meteorological effects, and the uncertainty of the time and height corrections for some of the smaller ports impose uncertainties which upset the apparent accuracy. In fact many yachtsmen do not use the Admiralty Tide Tables, but use tables in commercial almanacs, usually giving the times and heights of high water only.

The following method has been developed for use in a pilotage book for yachtsmen, covering the northern part of the Bay of Biscay. It could be adapted, with some loss of simplicity, to areas where the tides are less regular. It is based on the following assumptions:

(i) The mean tidal level (M.T.L.) is the same at a given place for all tides.

(ii) The range of the tide on a particular day is the same multiple of the local mean spring range at all places in the area covered.

(iii) The form of the curve of rise and fall of the tide is the same at all places in the area covered.

(iv) The interval between local H.W. and H.W. at the standard port is constant. 